\title{
Identity-by-descent refines mapping of candidate regions for preaxial polydactyly II /III in a large Chinese pedigree
}

\author{
Xingyan Yang ${ }^{1}$, Quankuan Shen ${ }^{2,3,4}$, Xierzhatijiang Sulaiman ${ }^{5}$, Hequn Liu², Minsheng Peng 2,3,4,6* \\ and Yaping Zhang $1,2,3,4,6^{*}$
}

\begin{abstract}
Preaxial polydactyly (PPD) is congenital hand malformation characterized by the duplication of digit. Herein, we scan the genome-wide SNPs for a large Chinese family with PPD-II/III. We employ the refined IBD algorithm to identify the identity-by-decent (IBD) segments and compare the frequency among the patients and normal relatives. A total of 72 markers of 0.01 percentile of the permutation are identified as the peak signals. Among of them, 57markers locate on chromosome 7q36 which is associated with PPD. Further analyses refine the mapping of candidate region in chromosome 7q36 into two $380 \mathrm{~Kb}$ fragments within LMBR1 and SHH respectively. IBD approach is a suitable method for mapping causal gene of human disease. Target-enrichment sequencing as well as functional experiments are required to illustrate the pathogenic mechanisms for PPD in the future.
\end{abstract}

Keywords: PPD, IBD, 7q36, LMBR1, SHH

\section{Main text}

\section{Background}

Preaxial polydactyly (PPD; OMIM\#188740) is characterized as complete or partial duplication of the thumb [1]. It is one of the most common congenital deformities [2]. The worldwide incidence of PPD is 1 in 3000 births [3]. The prevalence rate of polydactyly in Chinese ranks third in birth defects after congenital heart diseases and central nervous system diseases [4]. Polydactyly has genetic and clinical heterogeneity [2]. The mainstream treatment is resection for excess digits.

A series of efforts have been performed to investigate the genetic basis for PPD. Zguricas et al. conducted linkage analysis for Dutch, British, Turkish, Cuban pedigrees and mapped the candidate region to a $1.9 \mathrm{cM}$ interval between D7S550 and D7S2423 of 7q36 region [5]. Heus et al. further refined the candidate region to approximately $450 \mathrm{~Kb}$ including five genes: C7orf2 (i.e. LMBR1),

\footnotetext{
* Correspondence: pengminsheng@mail.kiz.ac.cn; zhangyp@mail.kiz.ac.cn ${ }^{2}$ State Key Laboratory of Genetic Resources and Evolution, Kunming Institute of Zoology, Kunming, China

${ }^{1}$ State Key Laboratory for Conservation and Utilization of Bio-resources in Yunnan, Yunnan University, Kunming, China

Full list of author information is available at the end of the article
}

C7orf3 (i.e. NOM1), C7orf4 (i.e. LINC00244), HLXB9 (i.e. $M N X 1)$ and RNF32 [6] by reconstructed a detailed physical map using a combination of exon trapping, cDNA selection, and EST mapping methods. Further evidence shows that PPD is caused by ectopic expression of $\mathrm{SHH}$ in mice, cats and humans [7]. The zone of polarizing activity regulatory sequence (ZRS), performs as the limbspecific cis-regulator, in controlling the expression of $S H H$. ZRS locates within intron 5 of the neighboring gene $L M B R 1$, which is $\sim 1 \mathrm{Mb}$ upstream from $S H H$ [8]. In a number of cases, mutations of ZRS disturb the expression of $S H H$ at the anterior limb bud margin and consequently caused PPD [8-15]. Homozygous deletion of ZRS can cause limb-specific absence of SHH expression in the acheiropodia [16]. It actually exists in the snake species and a limbless newt [17]. Duplication of ZRS results in Triphalangeal thumb-polysyndactyly syndrome (TPTPS; OMIM\#174500), that is a subtype of PPD. It also can lead to syndactyly type IV (SD4; OMIM\#186200) [18].

The common PPD only involves in hands/feet. In extreme and rare cases, PPD occur both in hands and feet. To investigate the genetic basis, $\mathrm{Li}$ et al. adopted a candidate gene approach to genotype nine 


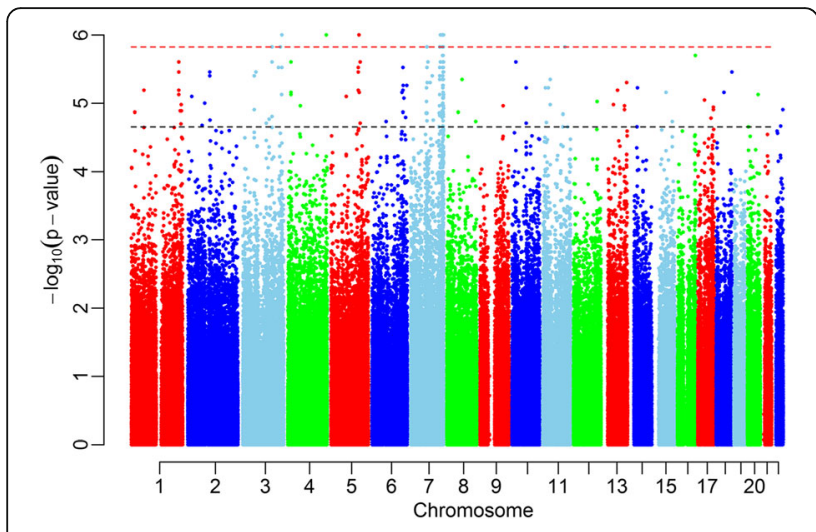

Fig. 1 Permutation analysis after filtering out regions with low IBD sharing. The black line indicates genome-wide threshold and the red line is the 0.01 percentile of the permutation

microsatellite markers of $7 \mathrm{q} 36$ chromosomal region in a Chinese family with PPD both in hands and feet. By linkage analysis and haplotype construction, they located the linked region spanning $1.7 \mathrm{Mb}$ between D7S2465 and D7D2423 [19]. It includes the $450 \mathrm{~kb}$ candidate region previously identified by Henus [6]. Nevertheless, the other parts of genome is not investigated yet. Herein, we genotyped genome-wide SNPs and employed the identity-by-descent (IBD) to refine the mapping of potential candidate loci for PPD in the same family.

\section{Methods}

\section{Patients}

This study has been approved by the internal review board of Kunming Institute of Zoology, Chinese Academy of Sciences (SMKX 2012013). The sixgeneration pedigree (including 21 patients and 24 normal relatives) involved in this study has been described previously in Li et al. [19]. All patients show hexadactyly of hands and feet. They have been diagnosed by physical examination \& X-ray and assigned as isolated PPD-II on hand and isolated PPD-III on feet according to Temtamy and McKusick's classification [20]. PPD shows autosomal dominant inheritance in this pedigree.

\section{SNP array}

We genotyped 900,015 markers in 45 individual with HumanOmniZhongHua-8 BeadChip v1.0 (Illumina). We exported the chip data in accordance with the reference sequence GRCh37 into PLINK format via GenomeStudio (Illumina). The markers on mitochondrial DNA and sex chromosomes were disregarded. We adopted a series of quality control strategies [21] by using PLINK 1.9 [22]. Two individuals with call rate $<90 \%$ were removed. The SNPs with call rate $<90 \%$, minor allele frequency $<1 \%$, and deviation of Hardy-Weinberg equilibrium $(P<1 \mathrm{e}-6)$ were excluded. After filtering, a total of 595,534 autosomal SNPs for 43 individuals were utilized in subsequent

Table 1 Genetic variants in the two IBD segments

\begin{tabular}{|c|c|c|c|c|c|c|}
\hline Gene(7q36)) & Position (GRCH37.p13) & SNP ID & REF & ALT & P-valve & Note \\
\hline \multirow[t]{9}{*}{ LMBR1 156470537...156685902 } & 156354434 & rs1860156 & $\mathrm{T}$ & C & $1.00 \mathrm{E}-06$ & $116 \mathrm{~kb}$ upstream of $\angle M B R 1$ \\
\hline & 156401455 & kgp6282999 & C & A & $1.00 \mathrm{E}-06$ & $69 \mathrm{~kb}$ upstream of LMBR1 \\
\hline & 156477347 & kgp13575466 & C & A & $1.00 \mathrm{E}-06$ & \\
\hline & 156497668 & rs10228997 & A & G & $1.00 \mathrm{E}-06$ & \\
\hline & 156526645 & rs10224728 & $\mathrm{T}$ & G & $1.00 \mathrm{E}-06$ & \\
\hline & 156686101 & kgp6457815 & C & $\mathrm{T}$ & $1.00 \mathrm{E}-06$ & 199 bp downstream of $L M B R 1$ \\
\hline & 156687282 & kgp1716770 & C & $\mathrm{T}$ & $1.00 \mathrm{E}-06$ & $1 \mathrm{~kb}$ downstream of $L M B R 1$ \\
\hline & 156716316 & kgp3747986 & $\mathrm{T}$ & C & $1.00 \mathrm{E}-06$ & $30 \mathrm{~kb}$ downstream of $L M B R 1$ \\
\hline & 156730688 & kgp7566181 & $\mathrm{T}$ & C & $1.00 \mathrm{E}-06$ & $45 \mathrm{~kb}$ downstream of $L M B R 1$ \\
\hline \multirow[t]{9}{*}{ SHH 155595558...155604967 } & 155103781 & rs13223383 & G & $\mathrm{T}$ & $1.00 \mathrm{E}-06$ & $492 \mathrm{~kb}$ upstream of $\mathrm{SHH}$ \\
\hline & $155,169,143$ & rs1990808 & C & $\mathrm{T}$ & $1.00 \mathrm{E}-06$ & $426 \mathrm{~kb}$ upstream of $\mathrm{SHH}$ \\
\hline & $155,182,442$ & kgp9710825 & G & A & $1.00 \mathrm{E}-06$ & $426 \mathrm{~kb}$ upstream of $\mathrm{SHH}$ \\
\hline & 155716520 & rs4716928 & C & $\mathrm{T}$ & $1.00 \mathrm{E}-06$ & $112 \mathrm{~kb}$ downstream of $\mathrm{SHH}$ \\
\hline & 155718241 & rs4716930 & A & C & $1.00 \mathrm{E}-06$ & $113 \mathrm{~kb}$ downstream of $\mathrm{SHH}$ \\
\hline & 155721324 & rs11764820 & A & G & $1.00 \mathrm{E}-06$ & $116 \mathrm{~kb}$ downstream of $\mathrm{SHH}$ \\
\hline & 155721386 & rs11769663 & G & $\mathrm{T}$ & $1.00 \mathrm{E}-06$ & $116 \mathrm{~kb}$ downstream of $\mathrm{SHH}$ \\
\hline & 155722231 & rs6971588 & $\mathrm{T}$ & G & $1.00 \mathrm{E}-06$ & $117 \mathrm{~kb}$ downstream of $\mathrm{SHH}$ \\
\hline & 155723112 & kgp11597900 & C & $\mathrm{T}$ & $1.00 \mathrm{E}-06$ & $118 \mathrm{~kb}$ downstream of $\mathrm{SHH}$ \\
\hline
\end{tabular}


Table 2 Pairwise statistics of LMBR1 and SHH

\begin{tabular}{|c|c|c|c|c|c|c|c|c|}
\hline \multirow[b]{2}{*}{ Gene } & \multicolumn{3}{|c|}{ patient-patient } & \multicolumn{3}{|c|}{ normal-normal } & \multicolumn{2}{|l|}{ patient-normal } \\
\hline & No. patient & $\begin{array}{l}\text { No.IBD in patient } \\
\text { pairs }\end{array}$ & $\begin{array}{l}\% \text { IBD in patient } \\
\text { pairs }\end{array}$ & No. normal & $\begin{array}{l}\text { No.IBD in normal } \\
\text { pairs }\end{array}$ & $\begin{array}{l}\text { \% IBD in normal } \\
\text { pairs }\end{array}$ & $\begin{array}{l}\text { No.IBD in patient- } \\
\text { normal pairs }\end{array}$ & $\begin{array}{l}\text { \% IBD in patient- } \\
\text { normal pairs }\end{array}$ \\
\hline LMBR1 & 21 & 84 & 0.400 & 22 & 17 & 0.074 & 29 & 0.126 \\
\hline $\mathrm{SHH}$ & 21 & 81 & 0.386 & 22 & 16 & 0.069 & 24 & 0.104 \\
\hline
\end{tabular}

$\%$ IBD patient pairs = IBD patient pairs $/$ case $\times($ case- 1$) / 2$

$\%$ IBD normal pairs $=$ IBD normal pairs $/$ normal $\times($ normal- 1$) / 2$

$\%$ IBD patient-normal pairs = IBD patient-normal pairs/case $\mathrm{x}$ normal $/ 2$

analyses. The data have been deposited into the Genome Variation Map [23] (GVM000001).

\section{IBD detection}

We used BEAGLE 4.0 [24] to phase and impute the genotype data referring to the pedigree information and the genetic map of HapMapII [25]. We detected the IBD segment with the refined IBD in BEAGLE 4.1 [26]. The IBD segment length shorter than $1 \mathrm{cM}$ and the logarithm of odds (LOD) score under 3 were excluded before permutation [27]. The threshold of the genomewide significance was set to the 0.05 percentile of the distribution of the permutation $p$-value.

\section{Results}

The length distribution of detected IBD segments approximates a Pareto distribution (Additional file 1: Figure S1). The permutation result shows the significant segments distributing widely across genomes (Fig. 1). When considering the top $0.01 \%$ outliers of signals, we find the peak signals of 72 SNPs, of which 57 markers locate at 7q36 chromosomal region (Additional file 2: Table S1). We map the markers into the IBD fragments including $L M B R 1$ and $S H H$ (Table 1). The minimal IBD segments within $L M B R 1$ and $S H H$ are around $380 \mathrm{~Kb}$, respectively (Additional file 3: Table S2). The IBD segments are more frequently in patient-patient (ratio; percentage) than normal-normal (ratio; percentage) (Table 2). We make annotation for the significant SNPs (Additional file 2: Table S1). All the SNPs are not haven't been reported to be associated with PPD before.

\section{Discussion}

Our IBD analyses refine the mapping of the candidate regions for PPD into two $\sim 380 \mathrm{~Kb}$ segments in $7 \mathrm{q} 36$ referring to $L M B R 1$ and $S H H$ genes, respectively (Additional file 3: Table S2). The segment for $L M B R 1$ includes three genes (i.e. LMBR1, NOM1, and RNF32) and lies within the $450 \mathrm{~kb}$ candidate region identified before [6].Mutations in the ZRS is playing an important role in the pathogenesis of PPD (Additional file 4: Table S3). The duplication of ZRS can cause TPTPS and SD4 [18]. Its role in PPD-II /PPD-III is unclear. In the previous investigation of the same family, Li et al. detected no pathogenic mutation in ZRS as well as no duplication of ZRS [19]. Consequently, the etiology of this PPD family may be another limb-specific regulatory element of $\mathrm{SHH}$ gene exists in the noncoding region.

In addition to the segment of $L M B R 1$, we also identified a segment of $S H H$. The $S H H$ gene encodes sonic hedgehog, a secreted protein, which plays a key role in the limb development [28]. The ectopic expression of $\mathrm{SHH}$ in the anterior limb margin can cause PPD in human, in mouse [29], Hemingway cat [7] and chicken [30]. Recently, Petit et al. identified a $2 \mathrm{~kb}$ deletion occurring about $240 \mathrm{~kb}$ upstream from the $S H H$ promoter in a large family with PPDhypertrichosis. They found the $2 \mathrm{~kb}$ deletion repress the transcriptional activity of the $S H H$ promoter in vitro [31]. It raises a possibility that long range regulation may be an explanation for the PPD. Further target-enrichment sequencing and further functional experiments for $L M B R 1$ and SHH are required to identify the pathogenic mutation(s).

In summary, we refine the mapping of the candidate regions for PPD based on high-density genomic SNPs. The potential candidate mutations are most likely to locate in $L M B R 1$ and/or $S H H$ gene. It is much improved compred with previous results $[6,19]$. Our study suggests that the IBD approach is a suitable method for mapping the causal genes of human diseases. Moreover, as disruptions of topological chromatin domains can result in limb malformations [32], more attention should be paid when studying PPD in the future on this aspect.

\section{Additional files}

Additional file 1: Figure S1. Plot of the distribution of the IBD segments.

Additional file 2: Table S1. Top 0.01\% peak signals.

Additional file 3: Table S2. IBD segments of $L M B R 1$ and $S H H$. Additional file 4: Table S3. Mutations in intron 5 of $L M B R 1$.

\section{Abbreviations}

IBD: Identity by descent; LINC00244: Long intergenic non-protein coding RNA 244; LMBR1: Limb development membrane protein 1; MNX1: Motor neuron and pancreas homeobox 1; NOM1: Nucleolar protein with MIF4G domain 1; PPD: Preaxial polydactyly; RNF32: Ring finger protein 32 


\section{Acknowledgments}

We thank the volunteers for participating in this research. We appreciate Ping Yu, Xiaoyi Yan, Yonggang Chen, Luhang Zhao for their efforts in sampling and related information collection. We thank Nini Shi for technical assistance. This study was supported by grants from National Natural Science Foundation of China and Bureau of Science and Technology of Yunnan Province. This work was also supported by the Animal Branch of the Germplasm Bank of Wild Species, Chinese Academy of Sciences (the Large Research Infrastructure Funding). MS.P. thanks the support from the Youth Innovation Promotion Association, Chinese Academy of Sciences.

\section{Funding}

The research protocol of the study entitled "Identity-by-descent Refines Mapping of Candidate Regions for Preaxial Polydactyly II/III in a Large Chinese Pedigree", has been reviewed and approved by the internal review board of Kunming Institute of Zoology, Chinese Academy of Sciences. This study was supported by grants from Bureau of Science and Technology of Yunnan Province, China.

\section{Availability of data and materials}

The variation data reported in this paper have been deposited in the Genome Variation Map (GVM) in Big Data Center, Beijing Institute of Genomics (BIG), Chinese Academy of Science, (GVM; http://bigd.big.ac.cn/ gvm/; accession numbers GVM000001)

\section{Authors' contributions}

$X Y$ analyzed the SNP array data and wrote the manuscript. IBD was carried out by XY and assisted by QS. XS revised the manuscript. HL performed experiments and provided patients data. MP participated in its design and revised the manuscript. All processes were guided by Dr. MP and Pro. YZ. All authors read and approved the final manuscript.

\section{Ethics approval and consent to participate}

This study has been approved by the internal review board of Kunming Institute of Zoology, Chinese Academy of Sciences (SMKX 2012013). The patients consent to participate in this study by signing a Consent Form allowing the use of biological samples and clinical data.

\section{Consent for publication}

A six-generation family consisting of 45 individuals including 21 affected members and 24 normal relatives was located in a rural area of Zhejiang Province, China. All patients show hexadactyly of hands and feet, diagnosed by physical examination \& X-ray. According to Temtamy and McKusick's classification it is classified as isolated PPD-II on hand and isolated PPD-III on feet. We used raw data have genotyped by Illumina HumanOmniZhongHua-8 BeadChip previously as based data for our next study. The results of the analysis of clinical data have been described previously in Li et al. Our manuscript does not contain any individual person's data.

\section{Competing interests}

The authors declare no conflict of interest.

\section{Publisher's Note}

Springer Nature remains neutral with regard to jurisdictional claims in published maps and institutional affiliations.

\footnotetext{
Author details

${ }^{1}$ State Key Laboratory for Conservation and Utilization of Bio-resources in Yunnan, Yunnan University, Kunming, China. ${ }^{2}$ State Key Laboratory of Genetic Resources and Evolution, Kunming Institute of Zoology, Kunming, China. ${ }^{3}$ Kunming College of Life Science, University of Chinese Academy of Sciences, Kunming, China. ${ }^{4} \mathrm{KIZ} /$ CUHK Joint Laboratory of Bio-resources and Molecular Research in Common Diseases, Kunming, China. ${ }^{5}$ Basic Medical College, Xinjiang Medical University, Ürümqi 830011, China. ${ }^{6}$ Kunming Institute of Zoology, Chinese Academy of Sciences, 32 Jiaochang Donglu, Kunming 650223, China.
}

Received: 26 March 2017 Accepted: 22 June 2017

Published online: 03 July 2017

\section{References}

1. Rayan GM, Upton III J. Congenital Hand Anomalies and Associated Syndromes. Springer; 2014.

2. Malik S. Polydactyly: phenotypes, genetics and classification. Clin Genet. 2014;85(3):203-12

3. Watt AJ, Chung KC. Duplication. Hand Clin. 2009;25(2):215-27.

4. Yan J, Huang G, Sun Y, Zhao X, Chen S, Zou S, et al. Birth defects after assisted reproductive technologies in China: analysis of 15,405 offspring in seven centers (2004 to 2008). Fertil Steril. 2011;95(1):458-60.

5. Zguricas J, Heus H, Morales-Peralta E, Breedveld G, Kuyt B, Mumcu EF, et al. Clinical and genetic studies on 12 preaxial polydactyly families and refinement of the localisation of the gene responsible to a $1.9 \mathrm{cM}$ region on chromosome 7q36. J Med Genet. 1999;36(1):32-40.

6. Heus HC, Hing A, van Baren MJ, Joose M, Breedveld GJ, Wang JC, et al. A physical and transcriptional map of the preaxial polydactyly locus on chromosome 7q36. Genomics. 1999;57(3):342-51.

7. Lettice LA, Hill AE, Devenney PS, Hill RE. Point mutations in a distant sonic hedgehog cis-regulator generate a variable regulatory output responsible for preaxial polydactyly. Hum Mol Genet. 2008;17(7):978-85.

8. Lettice LA. A long-range Shh enhancer regulates expression in the developing limb and fin and is associated with preaxial polydactyly. Hum Mol Genet. 2003;12(14):1725-35.

9. Wieczorek D, Pawlik B, Li Y, Akarsu NA, Caliebe A, May KJ, et al. A specific mutation in the distant sonic hedgehog $(\mathrm{SHH})$ cis-regulator (ZRS) causes Werner mesomelic syndrome (WMS) while complete ZRS duplications underlie Haas type polysyndactyly and preaxial polydactyly (PPD) with or without triphalangeal thumb. Hum Mutat. 2010;31(1):81-9.

10. Farooq M, Troelsen JT, Boyd M, Eiberg H, Hansen L, Hussain MS, et al. Preaxial polydactyly/triphalangeal thumb is associated with changed transcription factor-binding affinity in a family with a novel point mutation in the long-range cis-regulatory element ZRS. Eur J Hum Genet. 2010;18(6): 733-6.

11. Wang ZQ, Tian SH, Shi YZ, Zhou PT, Wang ZY, Shu RZ, et al. A single C to T transition in intron 5 of LMBR1 gene is associated with triphalangeal thumb-polysyndactyly syndrome in a Chinese family. Biochem Biophys Res Commun. 2007:355(2):312-7.

12. VanderMeer JE, Lozano R, Sun M, Xue Y, Daentl D, Jabs EW, et al. A novel ZRS mutation leads to preaxial polydactyly type 2 in a heterozygous form and Werner mesomelic syndrome in a homozygous form. Hum Mutat. 2014;35(8):945-8.

13. Semerci CN, Demirkan F, Ozdemir M, Biskin E, Akin B, Bagci H, et al. Homozygous feature of isolated triphalangeal thumb-preaxial polydactyly linked to 7q36: no phenotypic difference between homozygotes and heterozygotes. Clin Genet. 2009;76(1):85-90.

14. Furniss D, Lettice LA, Taylor IB, Critchley PS, Giele H, Hill RE, et al. A variant in the sonic hedgehog regulatory sequence (ZRS) is associated with triphalangeal thumb and deregulates expression in the developing limb. Hum Mol Genet. 2008;17(16):2417-23.

15. Zhao X, Yang W, Sun M, Zhang X. ZRS mutations in two Chinese Han families featuring triphalangeal thumbs and preaxial polydactyly. Zhonghua Yi Xue Yi Chuan Xue Za Zhi. 2016:33(3):281-5.

16. lanakiev P, van Baren MJ, Daly MJ, Toledo SPA, Cavalcanti MG, Neto JC, et al. Acheiropodia is caused by a genomic deletion in C7orf2, the human Orthologue of the Lmbr1 Gene. Am J Hum Genet. 2001;68(1): 38-45.

17. Sagai T, Masuya H, Tamura M, Shimizu K, Yada Y, Wakana S, et al. Phylogenetic conservation of a limb-specific, cis-acting regulator of sonic hedgehog ( Shh). Mamm Genome. 2004;15(1):23-34.

18. Sun M, Ma F, Zeng X, Liu Q, Zhao XL, Wu FX, et al. Triphalangeal thumbpolysyndactyly syndrome and syndactyly type IV are caused by genomic duplications involving the long range, limb-specific $\mathrm{SHH}$ enhancer. J Med Genet. 2008:45(9):589-95.

19. Li H, Wang CY, Wang JX, Wu GS, Yu P, Yan XY, et al. Mutation analysis of a large Chinese pedigree with congenital preaxial polydactyly. Eur J Hum Genet. 2009;17(5):604-10.

20. Temtamy SA, McKusick VA. The genetics of hand malformations. Birth Defects Orig Artic Ser. 1978;14(3):i-xviii. 1-619 
21. Anderson CA, Pettersson FH, Clarke GM, Cardon LR, Morris AP, Zondervan KT. Data quality control in genetic case-control association studies. Nat Protoc. 2010;5(9):1564-73.

22. Chang CC, Chow CC, Tellier LC, Vattikuti S, Purcell SM, Lee JJ. Secondgeneration PLINK: rising to the challenge of larger and richer datasets. Gigascience. 2015;4:7.

23. Members BIGDC. The BIG Data Center: from deposition to integration to translation. Nucleic Acids Res. 2017;45(D1):D18-D24.

24. Browning BL, Browning SR. Improving the accuracy and efficiency of identity-by-descent detection in population data. Genetics. 2013;194(2):45971.

25. International HapMap C, Frazer KA, Ballinger DG, Cox DR, Hinds DA, Stuve $\mathrm{LL}$, et al. A second generation human haplotype map of over 3.1 million SNPs. Nature. 2007:449(7164):851-61.

26. Browning BL, Browning SR. Refined IBD: a new method for detecting identity by descent in population samples. Genet Epidemiol. 2012;36(7):737.

27. Westerlind $\mathrm{H}$, Imrell K, Ramanujam R, Myhr K-M, Celius EG, Harbo HF, et al. Identity-by-descent mapping in a scandinavian multiple sclerosis cohort. Eur J Hum Genet. 2015;23(5):688-92.

28. Kvon Evgeny Z, Kamneva Olga K, Melo Uirá S, Barozzi I, Osterwalder M, Mannion Brandon J, et al. Progressive loss of function in a limb enhancer during snake evolution. Cell. 2016;167(3):633-42.

29. Hill RE, Heaney SJ, Lettice LA. Sonic hedgehog: restricted expression and limb dysmorphologies. J Anat. 2003;202(1):13-20.

30. Dunn IC, Paton IR, Clelland AK, Sebastian S, Johnson EJ, McTeir L, et al. The chicken polydactyly (Po) locus causes allelic imbalance and ectopic expression of Shh during limb development. Dev Dyn. 2011;240(5):1163-72.

31. Petit F, Jourdain AS, Holder-Espinasse M, Keren B, Andrieux J, DuterqueCoquillaud $\mathrm{M}$, et al. The disruption of a novel limb cis-regulatory element of $\mathrm{SHH}$ is associated with autosomal dominant preaxial polydactylyhypertrichosis. Eur J Hum Genet. 2016;24(1):37-43.

32. Lupianez DG, Kraft K, Heinrich V, Krawitz P, Brancati F, Klopocki E, et al. Disruptions of topological chromatin domains cause pathogenic rewiring of gene-enhancer interactions. Cell. 2015;161(5):1012-25.

\section{Submit your next manuscript to BioMed Central and we will help you at every step:}

- We accept pre-submission inquiries

- Our selector tool helps you to find the most relevant journal

- We provide round the clock customer support

- Convenient online submission

- Thorough peer review

- Inclusion in PubMed and all major indexing services

- Maximum visibility for your research

Submit your manuscript at www.biomedcentral.com/submit 